\title{
Darreres aportacions en l'ensenyament de la geografia a Catalunya i a Espanya
}

\author{
Rosa Maria Medir Huerta \\ Salvador Calabuig Serra \\ Universitat de Girona. Institut de Recerca Educativa \\ rosa.medir@udg.edu \\ salvador.calabuig@udg.edu
}

Rebut: juny de 2017

Acceptat: juliol de 2017

\section{Resum}

Aquest article té com a finalitat realitzar una cartografia de les aportacions principals que s'han fet en els darrers anys, a Catalunya i a Espanya, sobre la recerca de l'ensenyament de la geografia. Es tracta d'un estudi d'anàlisi documental que s'ha centrat en les revistes científiques principals sobre ensenyament i aprenentatge de la geografia. També s'hi han analitzat les publicacions derivades dels congressos i de les trobades de la Secció de Didàctica de la Geografia de l'Associació de Geògrafs Espanyols (AGE). Els principals camps de recerca tractats inclouen la presència de la geografia al currículum escolar; l'ensenyament competencial; l'educació per la sostenibilitat i altres desafiaments, i l'ús de la tecnologia. L'article acaba amb una reflexió sobre cap a on es dirigeix la docència de la geografia del futur.

Paraules clau: ensenyament de la geografia; recerca educativa; innovació pedagògica; didàctica de les ciències socials; currículum

\section{Resumen. Últimas aportaciones en la enseñanza de la geografía en Cataluña y España}

Este artículo tiene como finalidad realizar una cartografía de las principales aportaciones que se han llevado a cabo, en Cataluña y en España, acerca de la enseñanza de la geografía. Se trata de una investigación de análisis documental que se ha centrado en la revisión de las principales revistas científicas que tratan la enseñanza y el aprendizaje de la geografía. También se han analizado las contribuciones en publicaciones derivadas de congresos y encuentros organizados por la Sección de Didáctica de la Geografía de la Asociación de Geógrafos Españoles (AGE). Los principales campos de investigación que se abordan son: la presencia de la geografía en el currículo escolar; la enseñanza competencial; la educación para la sostenibilidad y los desafíos sociales y territoriales, y el uso de la tecnología. El artículo acaba con una reflexión acerca de hacia dónde va la enseñanza de la geografía en el futuro.

Palabras clave: enseñanza de la geografía; investigación educativa; innovación pedagógica; didáctica de las ciencias sociales; currículo 
Résumé. L'enseignement de la géographie en Catalogne et en Espagne: quelques recherches actuelles

Cet article propose une description des principales contributions à l'enseignement de la géographie réalisées en Catalogne et en Espagne pendant ces dernières années. Il s'agit d'une recherche documentaire focalisée sur la révision des principales revues scientifiques espagnoles relatives à l'enseignement et l'apprentissage de la géographie, ainsi que de publications issues de congrès et de séminaires organisés par la section géographie d'AGE. Les principaux domaines de recherche qui y sont abordés sont: la présence de la géographie dans les programmes scolaires, l'enseignement des compétences, l'éducation pour le développement durable, les défis sociaux et territoriaux ainsi que l'utilisation de la technologie. L'article se termine par une réflexion sur le futur de ces enseignements.

Mots-clés: Didactique de la Géographie; enseignement et apprentissage de la géographie; recherche documentaire; programmes scolaires

\section{Abstract. Geography education in Catalonia and Spain: Some current research}

This aim of this paper is to present the main contributions on geography education over the last decade in Catalonia and Spain. This research employs a documentary analysis methodology using data contained in articles of the main Spanish geography education journals and conference proceedings of the Spanish Geography Association (AGE). The paper is divided into sections according to the fields of research on which the current debates in geography education are centred, including the place of geography in the Spanish curriculum, the competence learning approach, education for sustainability and the use of technology. The authors conclude the review with a final reflection on future directions for geography education.

Keywords: geography education; educational research; innovation in education; social studies education; curriculum

\section{Sumari}

1. Introducció: objectiu i metodologia de la recerca

2. El currículum escolar i la presència de la geografia

3. Per un ensenyament competencial de la didàctica de les ciències socials i, per tant, de la geografia
4. L'ensenyament de la geografia davant del repte de l'educació per la sostenibilitat i altres desafiaments socials i territorials

5. La tecnologia en l'ensenyament de la geografia

6. Conclusions: cap on va l'ensenyament de la geografia? Cap on ha d'anar?

Referències bibliogràfiques 


\section{Introducció: objectiu i metodologia de la recerca}

El desenvolupament tecnològic, la reorganització geopolítica, la crisi econòmica i els canvis socials del segle XXI han reobert el debat sobre quina geografia cal treballar a les escoles i als instituts, així com de quina manera es pot repensar el procés d'ensenyament $\mathrm{i}$ aprenentatge.

L'objectiu del present article és mostrar els debats principals que han tingut lloc sobre aquesta qüestió, a més de les aportacions que hem trobat més significatives i que han estat generades en els diferents camps de recerca de l'ensenyament de la geografia. La investigació segueix una metodologia d'anàlisi documental. Els documents o les fonts principals que s'hi han utilitzat inclouen tres de les principals revistes dedicades a l'ensenyament de la geografia i les ciències socials a Espanya: Íber, Didáctica Geográfica i Enseñanza de las Ciencias Sociales. També s'hi han tingut en compte unes altres publicacions, com ara les editades per la Secció de Didàctica de la Geografia de l'Associació de Geògrafs Espanyols com a resultat d'alguns congressos realitzats. L'anàlisi se centra en la darrera dècada, és a dir, la que va de l'any 2008 al 2017.

Diversos autors, per exemple: Gerber (2001), Roberts (2006) i Granados Sánchez (2010a), classifiquen l'ensenyament de la geografia en diferents camps de recerca, però, en el nostre treball, hem elaborat la nostra pròpia classificació en base als resultats obtinguts, és a dir, a partir de delimitar els principals centres d'interès i tenint en compte el volum de literatura existent. Així, ens centrarem en el paper de la geografia al currículum d'educació primària i secundària a Catalunya i en el que comporta el desafiament d'ensenyar per competències. També mostrarem com la sostenibilitat $i$ altres desafiaments socials estan exercint un fort impacte en les temàtiques que es tracten en aquesta àrea i com les tecnologies digitals estan transformant, en molts casos, l'ensenyament de la geografia.

\section{El currículum escolar i la presència de la geografia}

Els geògrafs que es dediquen a la docència i, en particular, aquells que treballen en la didàctica de la geografia $i$ en la didàctica de les ciències socials, solen explicitar, a l'inici de les seves classes, que la geografia és una disciplina de síntesi amb una llarga presència a l'ensenyament $\mathrm{i}$ a les aules des que l'escola va prendre forma al llarg de la societat preindustrial i postindustrial. Si bé aquesta afirmació pot ser considerada certa, un estudi detallat de la història de la presència de la geografia al currículum acadèmic ens pot aportar diferències notables en èpoques diferents, en funció de les lleis educatives que han emmarcat la tasca del professorat a les aules. La geografia escolar ha estat explorada, per tant, al llarg de la història per autors com ara Melcón (1989a, 1989b, 1995), Luis i Romero (2007) i Souto (2012). Prenent en consideració les seves aportacions, ens adonem dels canvis lògics — en un sentit cronològic i disciplinari- de la presència d'aquesta àrea al currículum escolar.

Ens interessa ser conscients de quina geografia és present avui en els documents oficials curriculars. En el cas espanyol, ens referim a la Llei Orgànica 8/2013 
per a la millora de la qualitat educativa (LOMCE) i als decrets curriculars que se'n deriven: el Reial Decret 126/2014, de 28 de febrer, pel qual s'estableix el currículum bàsic de l'educació primària i el Reial Decret 1105/2014, de 26 de desembre, pel qual s'estableix el currículum bàsic de l'educació secundària obligatòria i del batxillerat. En l'àmbit de Catalunya, però, el currículum vigent és el que es regeix pels tres decrets corresponents, dos dels quals estan adaptats als mandats de la LOMCE (el de primària i el de la secundària obligatòria), i el tercer (el del batxillerat) avui encara es regeix pel decret de 2008, per tant, va ser promulgat abans de la LOMCE. Es tracta de les disposicions següents: per a primària, el Decret 119/2015, de 23 de juny; per a l'educació secundària obligatòria, el Decret 187/2015, de 25 d'agost, i per al batxillerat, de moment encara, el Decret $142 / 2008$, de 15 de juliol.

Començant per l'educació primària i en un sentit ampli, els canvis d'ubicació dels coneixements que es puguin considerar de geografia han estat importants. En primer lloc, la LOMCE ha fet desaparèixer l'àrea dita coneixement del medi natural, social $i$ cultural (que ha estat vigent aproximadament al llarg d'uns vint-i-cinc anys), no pas per configurar dues àrees de coneixement, sinó dues assignatures: ciències socials $i$ ciències de la naturalesa. Aquest canvi inicial ja ha estat posat en qüestió per diversos professionals, al mateix temps que n'hi ha hagut uns altres que han considerat que constitueix una oportunitat millor per potenciar i revitalitzar les potencialitats dels conceptes didàctics d'espai i de temps. Entre els primers, destaca l'opinió contrària de l'Associació Universitària del Professorat en Didàctica de les Ciències Socials, que agrupa la majoria de docents universitaris de l'Estat espanyol en aquesta àrea de coneixement. A la declaració de l'any 2014, hi expressen el següent:

[...] manifestamos nuestro desacuerdo con la LOMCE y el currículum diseñado para su desarrollo. En primer lugar, porque se han obviado los resultados de la investigación didáctica más reciente, que apuesta por un currículum globalizado, para retroceder cuarenta años atrás e implantar contenidos sociales disciplinares desde la educación primaria, de corte positivista, y ajenos a la complejidad religiosa, étnica, cultural y sexual del mundo actual. (AUPCS, 2014)

Entre els defensors d'aquest canvi, que ja s'havia anunciat en una llei anterior que no es va arribar a implantar a l'educació primària (ens referim a la Llei Orgànica 830/2003, de qualitat de l'educació, LOCE), podem citar la veu acreditada de M.J. Marrón Gaite, qui sempre ha defensat la separació de les dues àrees de coneixement en socials i naturals amb l'argumentació següent:

[...] desaparece la ambigüedad que ha caracterizado a esta área en el anterior currículo, en la que cabía todo y no se concretaba nada, lo que provocaba no pocas veces el desconcierto del profesorado y, sobre todo, el despiste de los alumnos, que habían convertido al "cono», como con frecuencia denominan al àrea, en una especie de cajón de sastre, sin referentes científicos claros en que apoyarse. (Marrón, 2003: 269) 
El debat entre aquestes dues posicions és obert des de fa temps i no s'ha recollit cap opinió unànime entre el professorat, ni en un sentit ni en l'altre. Les evidències recollides de la seva opinió, si bé sembla que es decantin cap a la preferència d'una àrea única, no arriben a cap consens en referència a les argumentacions ni sembla que s'acostin a la millora de les competències específiques (competències científiques i competència social i ciutadana). La conclusió a la qual s'arriba és que el canvi de denominació de l'àrea és un factor més d'indefinició de la matèria que cal impartir (De Miguel, 2014).

En aquest nou currículum de «ciències socials» com a assignatura, hi trobem quatre blocs de coneixement: continguts comuns, el món on vivim, viure en societat i les petjades en el temps. La presència de la geografia és evident en el segon i en el tercer blocs. En el del món on vivim, quasi tots els continguts desglossats formen part de la geografia física, i el bloc de viure en societat reuneix els continguts més típics de la geografia humana, amb algunes referències que podríem fer derivar directament de l'economia i de les ciències polítiques.

Aquest currículum de caire estatal ha de ser desenvolupat a cada comunitat autònoma. Aquí trobem una varietat ingent de propostes, que no és objecte d'aquest article i que ens remeten al millor estudi comparatiu localitzat, amb una conclusió interessant: la major part dels currículums autonòmics són d'un detall i d'una extensió exagerada, ben diferent de la majoria de currículums de molts països europeus, amb desenvolupaments acadèmics molt més curts que propicien l'autonomia, la creativitat, la llibertat dels equips docents $\mathrm{i}$, en definitiva, la innovació pedagògica (De Miguel, 2014).

A Catalunya, en conflicte permanent amb l'Administració educativa estatal, el currículum de primària es va detallar molt més tard que a la resta de comunitats autònomes: a finals de juny de 2015. Davant la confrontació entre una o dues àrees, el currículum català segueix utilitzant la nomenclatura de coneixement del medi (el cita com a àmbit), defineix una sola àrea anomenada coneixement del medi natural i coneixement del medi social $i$ cultural, però es veu obligat a detallar continguts específics per separat i per nivells o cicles. A tots els cursos, els continguts geogràfics fan referència "al món que ens envolta» i a "persones, cultures i societats». La relació és detallada i hi podem trobar continguts de geografia física i humana, adaptats sempre amb frases possibles d'ajustar als aprenentatges necessaris per als nens i les nenes dels 6 als 12 anys.

Ara bé, el desplegament curricular a Catalunya és organitzat a partir de les competències definides. Així, es pretén que el professorat segueixi la mateixa línia en les seves programacions d'aula, considerades, avui en dia, més importants que la relació de continguts. La nostra experiència ens indica que la tasca ha esdevingut molt més complicada per al professorat, que es troba perdut a causa d'una nomenclatura cada vegada més àmplia i amb una incertesa constant de si les seves classes habituals són lluny o a prop dels requeriments competencials dels documents oficials.

Si llegim en clau geogràfica les tretze competències definides, i encara més enllà, si les llegim en clau de ciències socials, considerem que són les vuit següents les que s'adeqüen a les temàtiques de la geografia: 
1. Competència 1: plantejar-se preguntes sobre el medi, utilitzar estratègies de cerca de dades i analitzar resultats per trobar-hi respostes.

2. Competència 2: interpretar el present a partir de l'anàlisi dels canvis i de les continuïtats al llarg del temps, per comprendre la societat en què vivim.

3. Competència 3: interpretar l'espai a partir dels elements del territori i de les seves representacions per situar-s'hi i desplaçar-s'hi.

4. Competència 4: analitzar paisatges i ecosistemes atenent els factors socials i naturals que els configuren, a fi de valorar les actuacions que els afecten.

5. Competència 5: avaluar problemes socials rellevants interpretant-ne les causes i les conseqüències per plantejar propostes de futur.

6. Competència 11: adoptar hàbits sobre l'adquisició i l'ús de béns i serveis, amb coneixements científics i socials per esdevenir un consumidor responsable.

7. Competència 12: participar en la vida col-lectiva a partir de valors democràtics, per millorar la convivència i per afavorir un entorn més just i solidari.

8. Competència 13: valorar el sistema democràtic partint del coneixement dels sistemes polítics per esdevenir futurs ciutadans crítics.

A l'etapa de l'educació secundària obligatòria, la LOMCE estableix dos cicles (el primer cicle, de primer a tercer, i el segon cicle, el quart curs, amb dues modalitats). La geografia i la història com a assignatura és una matèria del bloc d'assignatures troncals a tots els cursos de l'ESO. Per al primer cicle, s'estableixen tres blocs de continguts: el medi físic, l'espai humà i la història. Per al segon cicle (quart d'ESO), s'estableixen deu blocs, dels quals només els dos finals podem relacionar amb la geografia (la revolució tecnològica i la globalització, i la relació entre el passat, el present i el futur a través de la història i la geografia). Els continguts estan estructurats segons la clàssica i enciclopèdica divisió entre geografia física i geografia humana. Els qui els han analitzat, valorat i comparat amb altres currículums europeus (De Miguel, 2016) denuncien que no hem sortit d'una geografia memorística; que els continguts esmentats són sempre conceptuals i que els procedimentals i actitudinals es troben només en els criteris d'avaluació; que no propicia l'anàlisi espacial dels fenòmens geogràfics complexos; que no hi apareix res sobre la tecnologia geoespacial, la geoinformació ni la geomèdia, i que, per tant, la idea potent $\mathrm{i}$ emergent en d'altres països de la ciutadania espacial hi és inexistent.

Igualment, les comunitats autònomes tenen la responsabilitat de desplegar aquest currículum, detallant-ne més els continguts, els criteris d'avaluació i les competències, així com fixar la distribució horària del conjunt d'assignatures d'ESO i de batxillerat. Els problemes són tan importants o més que al currículum de primària, $\mathrm{i}$ estem d'acord a afirmar que mai com ara la prescripció del pla d'estudis havia estat tan condicionada per l'orientació política (De Miguel, 2016).

A Catalunya, s'hi han especificat competències, continguts i criteris d'avaluació. Són tretze competències de l'àrea anomenada ciències socials: geografia 
i història, de les quals tres són clarament geogràfiques i tres més formen la dimensió ciutadana. Les tres competències geogràfiques són les següents:

1. Competència 5: explicar les interrelacions entre els elements de l'espai geogràfic, per gestionar les activitats humanes en el territori amb criteris de sostenibilitat.

2. Competència 6: aplicar els procediments de l'anàlisi geogràfica a partir de la cerca i l'anàlisi de diverses fonts, per interpretar l'espai i prendre decisions.

3. Competència 7: analitzar diferents models d'organització política, econòmica i territorial, com també les desigualtats que generen, per valorar com afecten la vida de les persones i fer propostes d'actuació.

Els continguts que hi apareixen esmentats tracten sobre els aspectes següents: a primer curs, el medi físic, des de l'àmbit mundial fins al de Catalunya; a segon curs, l'ocupació del territori: població i societat; a tercer curs, l'activitat econòmica i l'organització política, i a quart curs, el món actual i la globalització.

A l'etapa de batxillerat, encara avui, segueix vigent el currículum de 2008 (per tant, no està adaptat a la LOMCE), amb una assignatura anual de geografia a la modalitat d'humanitats i ciències socials.

Els experts provinents de l'àmbit de la geografia opinen que aquesta matèria ha perdut pes constantment en relació amb la història, que el currículum no té una bona consistència ni cap justificació epistemològica i que no propicia en absolut la innovació pedagògica (De Miguel, 2016).

En aquest context curricular, dubtós i incòmode sovint per al professorat, veurem que les aportacions innovadores abracen tots els camps de la geografia, encara que en fem una selecció en aquest article, en funció del que els autors considerem com a més representatiu de l'actualitat geogràfica i docent alhora.

\section{Per un ensenyament competencial de la didàctica de les ciències socials i, per tant, de la geografia}

En l'actualitat, i des d'aproximadament l'any 2006, la normativa educativa ha incorporat una nova perspectiva basada en el desenvolupament de competències. Si bé la formulació de competències bàsiques té el seu origen en un model capitalista neoliberal promogut per organitzacions internacionals com ara l'OCDE, la UE i el Banc Mundial, cal reconèixer que les lleis educatives de diversos països, i també les d'Espanya, han incorporat perspectives integradores i humanistes — com ara la ciutadania activa - a les idees economicistes, competitives i de cultura de la responsabilitat d'aprendre de forma totalment individual que provenen dels orígens esmentats (López Facal, 2013).

Considerant una persona competent aquella que sap aportar solucions intel-ligents als problemes que li presenta la vida, per la qual cosa necessita recórrer als seus coneixements, com també a tècniques i a estratègies diverses, creiem que la geografia ha de ser una de les matèries més idònies per formar 
ciutadans més competents en un sentit social i crític, no solament atenent el punt de vista econòmic. Els coneixements socials que aporta la geografia esdevenen imprescindibles per formar aquest tipus de ciutadans. Tenint en compte això, recollim algunes aportacions d'autors nacionals que van clarament en aquesta direcció.

El treball d'Olga Moreno i Francisco Garcia (2013) ens exposa com tres experiències educatives desenvolupades a Andalusia constitueixen bases segures per al desenvolupament d'una ciutadania planetària, considerant-la, aquesta, com una de les competències bàsiques que cal formar durant l'escolaritat. Els autors reconeixen el següent:

[...] la geografía, dentro de las ciencias sociales, constituye un campo de referencia fundamental por cuanto aborda los problemas desde la dimensión espacial, permitiendo tanto ese abordaje de los mismos en diferentes escalas como el análisis de las interacciones entre los problemas socio-ambientales y el entorno en el que se generan y manifiestan. (Moreno i Garcia, 2013: 10)

Podem recórrer a exemples concrets de desenvolupament de classes de geografia als cursos d'ESO que compleixen, donen força i concreten la competència social i ciutadana, com els que presenta María Blay (2013); podem comprovar com hi ha continguts geogràfics tan genuïns com l'observació de paisatges de l'entorn, l'estudi de la població local o com el món global dins del món local s'adeqüen totalment al desenvolupament de la competència social i ciutadana (a més d'altres). Especialment detallada és la proposta per a l'estudi de la ciutat que van elaborar a tercer d'ESO des de l'Aragó a l'inici dels anys de la instauració de les competències. Es tracta de l'aportació de Javier Velilla (2007), portada a terme en un IES de Saragossa. En referència al nivell de batxillerat, destaquem la proposta de Xosé Carlos Macía (2013), que planteja treballar amb la cartografia de la Unió Europea en l'ensenyament de la geografia.

Per l'antiguitat i la continuïtat que presenta, no podem deixar d'esmentar el projecte Gea-Clio (amb més de vint anys d'existència), dut a terme per un grup de professorat de nivells educatius diferents de la Comunitat Valenciana que ha treballat sempre l'ensenyament de la geografia a favor d'una formació ciutadana, situant-se, això sí, en la consecució d'objectius socials i prenent, per tant, la visió competencial que possibilita aquesta línia, no pas la que porta a la competitivitat i l'individualisme. Els llibres de text i els materials per al professorat publicats per aquest grup busquen fer palesa la necessitat de relacionar les activitats didàctiques amb els problemes socials i ambientals percebuts per la ciutadania (Souto, 2011).

Aprendre de forma competencial va associat a una reforma metodològica que els docents han de voler portar a la pràctica. N'assenyalem aquí un dels mètodes més coneguts, com a mínim en teoria, si bé sovint ha estat portat a la pràctica de manera parcial. Ens referim a l'aprenentatge cooperatiu, i escollim l'aportació de Federico Prieto (2012) com un exemple complet d'aprenentatge cooperatiu formal, un model que aporta valors socials nous (solidaritat, respecte 
a la diversitat, cooperació, participació, responsabilitat, etc.) que són bons per als adolescents.

Amb una relació idònia amb la geografia, ens hem de fer ressò del mètode d'aprenentatge basat en projectes (ABP), estratègia metodològica que promou una actuació activa per part dels estudiants. Basant-se en el treball cooperatiu, la recerca d'informació i la presentació i la difusió dels treballs elaborats, posa l'èmfasi en l'alumnat, a qui concedeix l'autonomia i la capacitat de decisió, i se situa el docent en el lloc de guia i d'acompanyant. Els antecedents de l'ABP se situen a finals del segle XIX i principis del XX, dins l'Escola Nova i de la mà dels pedagogs Dewey i Kilpatrick, com tantes altres «innovacions» d'avui, que les trobem ja en èpoques ben remotes però que no s'han generalitzat en els sistemes educatius. Val la pena recórrer a l'article de Mercedes de la Calle (2016) per situar-nos correctament en aquesta metodologia dins de la geografia.

Com no pot ser d'altra manera, la geografia s'ha associat a la tecnologia. Cal parar esment al fet que, en els darrers anys, l'explosió de nous recursos vinculats a la informació geogràfica ha estat espectacular. La geoinformació, en la qual participa amb generositat l'alumnat de secundària, és fonamental per adquirir la competència d'aprendre a aprendre, la més relacionada amb l'aprenentatge autònom i l'ensenyament actiu. Rafael de Miguel (2013) ens explica com l'ús de la geoinformació contribueix a promoure l'aprenentatge per descobriment, la competència d'un pensament espacial i la competència per a una ciutadania espacial. Per aquest autor:

[...] la competencia en ciudadanía espacial significa preparar al alumno para la vida adulta en todos sus aspectos: para dominar tecnologías que puede acabar utilizando en su vida diaria o en su trabajo, para aprender a utilizar y compartir información geográfica digital, pero sobre todo para que ésta contribuya a la adquisición de responsabilidades y de la ciudadanía activa, que se traduzcan en acciones positivas sobre el territorio. (De Miguel, 2013: 31)

\section{L'ensenyament de la geografia davant del repte de l'educació per la sostenibilitat i altres desafiaments socials i territorials}

La sostenibilització del currículum de geografia a l'educació secundària ha estat àmpliament treballat per Jesús Granados Sánchez (2010a, 2010b, 2011). A la seva tesi doctoral (Granados Sánchez, 2010b), hi desenvolupa un marc teòric ampli que fonamenta una proposta de model sobre com es pot reorientar l'ensenyament de la geografia per educar per al desenvolupament sostenible i ho contextualitza a l'ESO a Catalunya. Així, explora el significat del concepte de desenvolupament sostenible, defineix què s'entén per educació per la sostenibilitat i es planteja uns criteris sobre què i com cal ensenyar geografia per fer adquirir les competències geogràfiques que estima que són necessàries per viure de forma sostenible. El model resultant planteja criteris o recomanacions per definir finalitats i competències, seleccionar continguts, tractar l'espai i l'escala geogràfica i analitzar quin model d'ensenyament-aprenentatge cal escollir. La 
suma de tots aquests criteris i recomanacions intenta fer que l'ensenyament de la geografia per la sostenibilitat promogui un pensament sistèmic i complex. El coneixement rellevant que suggereix l'estructura a partir dels conceptes clau de la geografia (natura-cultura, espai, escala, canvi i evolució, i consciència social (agència- estructura)) i dels conceptes clau de l'educació per la sostenibilitat (interdependència, escala geogràfica i relacions d'escala, context, canvi, democràcia, organització social, governança, ciutadania, realització humana, benestar, diversitat, risc, incertesa, principi de precaució, impacte, conflicte, perspectiva temporal i projecció). La metodologia d'ensenyament-aprenentatge que desenvolupa se centra en l'aprenentatge participatiu per assolir l'acció responsable i de servei, el qual ha de promoure l'acció cooperativa, el treball de camp, l'ús de les noves tecnologies i la interdisciplinarietat.

Durant els darrers deu anys, hem viscut un temps de crisi econòmica forta, al llarg de la qual el professorat de geografia s'ha plantejat també com l'ensenyament de la seva matèria s'havia d'adaptar a aquests temps i com podia contribuir a facilitar una millora social mitjançant la formació de ciutadans crítics. No és una novetat per a la geografia, molts autors ho recollien també en èpoques de bonança econòmica, però, en els temps presents, aquesta necessitat esdevé més palesa. Els docents es plantegen quins continguts de geografia cal seleccionar d'acord amb l'evolució de la pròpia ciència i en relació amb les necessitats socials (De la Calle, 2012). De quina manera es pot fer entrar la crisi econòmica a les aules com un contingut propi de la geografia i de la història és la proposta de Souto i López Facal (2016), els quals ens descriuen unes pautes d'actuació per al professorat. D'altra banda, Buzo (2016) ens explica l'ús de determinats materials i recursos, a més d'utilitzar les xarxes socials i la cartografia territorial de les desigualtats, tot plegat per treballar la crisi econòmica a les aules de secundària i de batxillerat. També, en referència a la crisi, Martínez (2016) ens planteja una proposta de programació completa. Opina que estudiar la crisi econòmica i explicar-la als adolescents és una decisió per part del professorat que fuig de les explicacions positivistes dels llibres de text i pren la responsabilitat de mostrar que no hi ha interpretacions úniques de la situació econòmica i que les qüestions socials són complexes, però no inexplicables.

Un dels punts d'acord és, sens dubte, que ens trobem en un món global $i$, per tant, que cal combinar escales geogràfiques. En aquest sentit, Batllori (2011) planteja la metodologia de combinar la gran escala amb l'escala petita, ja que proporciona una visió més complexa de la realitat, amb aplicació a l'etapa de primària $\mathrm{i}$ a la de secundària.

Igualment, en aquests anys, es reforça l'atenció que es presta a les temàtiques derivades dels processos de globalització, com ara la pobresa, els nous espais rurals, les zones vulnerables, el que és invisible i intangible i el que és efímer i marginal en la societat. Aquestes temàtiques, justament, ja havien estat definides poc temps abans de la crisi econòmica a les propostes de Nogué i Romero (2006). Reconeixem, però, que un currículum renovat, que faci evident un to més crític amb les disparitats socioeconòmiques o amb els 
problemes ambientals i que doni més visibilitat a les temàtiques marginals de la geografia, no s'ha generalitzat ni en les propostes curriculars dels territoris ni en les programacions d'aula. Tal com ens explica Claudino (2015), és un dels reptes pendents per a les ciències socials en l'àmbit escolar. Però, cercant una aportació real, com a mostra de la importància de la inclusió d'aquestes temàtiques, hem de citar la proposta de Call et al. (2015) sobre l'estudi de la pobresa a tercer curs d'ESO, unitat didàctica portada a terme en dos instituts de secundària de Catalunya situats en contextos diferents. Les autores justifiquen la necessitat d'incorporar al currículum les qüestions socials rellevants, contextualitzen la seva proposta en funció dels Objectius de Desenvolupament del Mil.lenni («Objectiu 1: eradicar la pobresa extrema i la fam»), utilitzen les tecnologies de la informació i la comunicació i se situen en un disseny competencial.

L'educació intercultural i la globalització apareixen també sovint a les classes de geografia en aquests darrers temps, i autors com ara Ramiro (2009) s'han preocupat d'apostar per treballar la immigració a diferents nivells de l'ensenyament, començant per la formació del professorat, cosa que en possibilitarà la transferència a l'educació primària i a la secundària.

L'educació per a la ciutadania, totalment coherent amb la competència més pròpia de l'àrea, és present en gran quantitat de propostes programàtiques per a l'educació primària, l'educació secundària i el batxillerat. Continguts, procediments, valors, de geografia i d'història; possiblement l'àmbit on més còmodament es troben aquestes dues disciplines. Un desafiament territorial, també. Una de les aportacions més diàfanes sobre com cal plantejar aquesta temàtica és la d'Armas i López Facal (2012).

\section{La tecnologia en l'ensenyament de la geografia}

Segons Horacio Capel (2012), ha nascut la neogeografia, un paradigma nou sorgit a conseqüència de la generalització de les tecnologies geogràfiques $\mathrm{i}$ l'accés a gran quantitat de recursos espacials. La geografia s'ha reinventat. D'aquesta nova caracterització de la disciplina, se'n desprèn que la seva transposició didàctica també ha d'avançar en aquest sentit. De fet, en els darrers anys, s'han obert línies d'investigació que publiquen treballs sobre la introducció de les tecnologies geogràfiques a les aules o en la formació inicial dels docents. El grup de didàctica de la geografia de l'AGE els ha classificat amb el terme d'educació geogràfica digital i ha dedicat una edició de les jornades anuals a aquestes propostes (De Miguel et al., 2012).

Sembla que podem situar els inicis de la revolució digital a l'ensenyament de la geografia cap a l'any 2000. Aleshores comencen a aparèixer, de manera aillada i molt espaiada en el temps, comunicacions i articles sobre els SIG a l'educació. Així, José Antonio Padilla Ángel publica la comunicació titulada Urbanita 2000: Conoce las ciudades desde el espacio, en la qual l'autor proposa abandonar les metodologies tradicionals en la didàctica de la geografia i incorporar-hi les digitals. Més endavant, l'any 2006, l'AGE ja dedica, al 
Tercer Congrés Ibèric, un apartat dedicat a les noves tecnologies de la informació i la comunicació a l'ensenyament-aprenentatge de la geografia, en el qual ja apareixen aplicacions didàctiques dels SIG i dels globus virtuals. A partir d'aquestes dates, ja és habitual trobar investigacions publicades sobre tecnologies i didàctica de la geografia: Rojo (2013) n'explicita bones pràctiques d'aula, entre les quals destaca les aplicacions de l'Atlas Escolar Digital, un projecte desenvolupat a partir del programa ArcGIS en línia, que pretén que els alumnes es familiaritzin amb els sistemes d'informació geogràfica, desenvolupin l'aprenentatge per descobriment, facin projectes d'anàlisis espacial i treballin de manera col-laborativa. Rojo (2013) es planteja com l'ús dels SIG en educació està aportant múltiples avantatges al desenvolupament del pensament espacial de l'alumnat, tal com diu que demostren diverses investigacions fetes als EUA i al Regne Unit. Per tant, cita diversos programes internacionals i nacionals a través del quals es porta a terme el treball dels SIG a l'aula. Entre els nacionals, parla del Portal Educatiu en Sistemes d'Informació Geogràfica (PESIG) de la Universitat de Girona, proposta de Boix i Olivella (2007). Utilitzar els SIG a l'aula implica servir-se de la metodologia d'aprenentatge basat en problemes (ABP), la qual cosa propicia el desenvolupament del pensament crític entre l'alumnat i les habilitats d'anàlisi, síntesi i avaluació.

És fonamental l'aportació de López Fernández i Martínez Medina (2016) per conèixer de primera mà com s'han anat incrementant les publicacions dedicades a la utilitat didàctica de la cartografia digital i els diferents sistemes d'informació geogràfica (SIG) en l'àmbit de la geografia, gràcies al desenvolupament del programari lliure i els recursos existents a Internet. Els autors han analitzat els treballs editats pel grup de didàctica de l'AGE i els publicats a la revista Didáctica Geográfica i constaten com l'educació secundària es presenta com l'etapa per a la qual es proposa una quantitat més elevada d'activitats didàctiques. També recorden que eines simples com ara Google Earth o Google Maps poden ser utilitzades amb comoditat a l'educació primària, però, malauradament, es lamenten de la falta d'experiències en aquesta etapa. Entre les moltes referències que recull aquest treball, en volem citar només les que marquen un camí per als propers anys. Per exemple, l'aplicabilitat didàctica dels SIG queda definida per De Lázaro i González (2005), els quals desgranen els avantatges i els inconvenients i expliciten els recursos disponibles a Internet en aquell moment. Es consolida la línia de treball amb l'article de De Miguel (2013) citat anteriorment, que descriu com les eines de cartografia digital contribueixen a desenvolupar una metodologia activa i afavoreixen aprenentatges significatius per descobriment, juntament amb competències d'autonomia i de reflexió espacial. Granados Sánchez i Lamagrande (2010) presenten una taxonomia de nou usos didàctics diferents que es poden fer de les tecnologies digitals, les quals condueixen a diferents tipus de processos cognitius que són claus en l'alfabetització digital. La proposta vol fer veure al professorat que hi ha diverses maneres d'utilitzar l'ampli ventall de recursos existents. 
Al llarg dels darrers anys, a més dels mapes digitals, s'hi han incorporat unes altres temàtiques. La ludificació, o l'aprenentatge basat en jocs, és una de les més recents. Consisteix a fer servir les tècniques dels jocs en ambients escolars o educatius i no lúdics (Ayén, 2017). És a dir, es tracta de generar en l'alumne les mateixes emocions i sentiments que li produeixen els jocs, tant els tradicionals com els electrònics. Es tracta de reproduir en l'àmbit educatiu la sensació de superació de reptes, les bonificacions amb premis (digital badgets), l'augment de nivell, etc. L'Horizon Report (Johnson et al., 2014) presenta la ludificació com una de les estratègies didàctiques que esdevenen claus per a l'ensenyament en els propers anys. De moment, hi ha poca literatura sobre com es poden aplicar a l'aprenentatge de la geografia les sensacions que requereix la ludificació, tot i que trobem algunes aportacions sobre l'ús didàctic dels videojocs a ciències socials (Jiménez-Palacios i Cuenca, 2015) i sobre programes concrets com ara Minecraft (Guevara i Colomer, 2017). La revista Iber va dedicar un monogràfic, el número 86 , a la ludificació en ciències socials. Ayén (2017) explica què és la ludificació i l'aprenentatge basat en jocs, i altres articles mostren exemples concrets sobre l'ús dels jocs, com ara Minecraft, Eduloc, Libertus o l'aplicació per a mòbils anomenat Game in Florence.

L'aprenentatge amb dispositius mòbils (anomenat $m$-learning en anglès) tampoc no és gaire present a les investigacions. Trobem alguns exemples sobre consideracions metodològiques de l'aprenentatge en línia per ensenyar geografia o les aplicacions pràctiques corresponents (López Fernández i Martínez Medina, 2016). En aquest sentit, encara manquen estudis sobre l'ús dels dispositius mòbils personals en l'aprenentatge, com ara telèfons intel.ligents o tauletes. Aquesta metodologia, anomenada també BYOD (Bring Your Own Device), que està basada en l'ús didàctic dels dispositius habituals, es creu que serà una de les tendències de futur per als propers anys.

Respecte a l'ús del GPS, a part de les aplicacions didàctiques de geocerca, hi ha experiències amb aplicacions per a telèfons intel-ligents sobre itineraris guiats, de les quals es treu un aprofitament pedagògic (Rodríguez Domenech, 2014). En són un exemple els projectes App educa CR i LUCAtrails.

Un dels camps explorats més recents és l'aplicació de la realitat augmentada. Hi ha un primer intent d'analitzar les possibilitats i les dificultats d'utilitzar-la en la didàctica de la geografia (Molina de la Torre et al., 2016), i és d'esperar que, atès el potencial que brinda per a la comprensió dels fenòmens espacials, es desenvolupin estudis sobre la seva pràctica, especialment en el treball de camp.

Una altra de les tecnologies que Horizon Report preveu que ha de gaudir d'un protagonisme important en l'educació són les xarxes socials, recurs que encara està per explotar. Així doncs, trobem alguns estudis sobre l'us del Twitter en l'educació superior (Calabuig et al., 2013), com també unes reflexions sobre la seva utilitat pedagògica, però el valor educatiu que pot tenir encara no és apreciat per la comunitat científica especialitzada en la didàctica de la geografia. 
Si bé alguns articles ho esmenten de passada, no hi ha cap investigació per validar el model TPACK en el camp de la geografia. Aquest patró proposa un enfocament per relacionar els continguts de les assignatures amb la didàctica corresponent i amb l'ús de les tecnologies. És a dir, els professors, a més de conèixer la disciplina i el seu procés d'ensenyament $\mathrm{i}$ aprenentatge, han de ser aptes per aplicar les tecnologies en aquest procés (Adell, 2012). Establir les bases de l'enfocament TPACK en la didàctica de la geografia podria servir de guia per utilitzar les tecnologies en aquest àmbit.

\section{Conclusions: cap on va l'ensenyament de la geografia? Cap on ha d'anar?}

Com hem vist, actualment, l'ensenyament de la geografia està situat en una cruilla on trobem camins plens d'oportunitats i camins amb amenaces serioses. Entre les oportunitats, hi veiem totes les reflexions d'autors que fan avançar la disciplina, que intenten que sigui significativa i que tingui un paper determinant en l'educació dels joves. Les tecnologies digitals han revolucionat també l'ensenyament de la geografia, de manera que han fet possible que es pugui accedir als recursos cartogràfics, a l'obtenció d'imatges i a la informació a temps real, a més de facilitar que es processi la informació i que es presenti utilitzant mitjans i registres diferents. Ara bé, també hem d'estar alerta dels perills que, com apunta Rafael de Miguel (2016), signifiquen la prescripció i la involució del currículum escolar, a més de la desatenció de la innovació i el progrés epistemològic de la didàctica de la geografia per part dels seus especialistes.

\section{Referències bibliogràfiques}

ADELL, J. (2012). «Diseño de Actividades según el TPACK». A: Diseño de actividades didácticas con TIC [arxiu de vídeo]. <https://www.youtube.com/watch?v=5mi2D7WTMXI\&t=3s>

ADELL, J. i CASTAÑEDA, L. (2012). «Tecnologías emergentes, ¿pedagogías emergentes?». A: HernándeZ, J.; Pennesi, M.; Sobrino, D. i VÁZqueZ, A. (eds.). Tendencias emergentes en educación con TIC. Barcelona: Asociación Espiral. Educación y Tecnología, 13-32.

ARMAS, J. i LOPEZ FACAL, R. (2012). «Ciencias sociales y educación para la ciudadanía: Un dialogo necesariom. Íber: Didáctica de las Ciencias Sociales, Geografia e Historia, 71, 84-91.

AUPCS (2014). AUPDCS ante la LOMCE [en línia] <http://didactica-ciencias-sociales.org/aupdcs-ante-la-lomce/>.

AYÉn, F. (2017). «QQué es la gamificación y el ABJ?». Íber: Didáctica de las Ciencias Sociales, Geografia e Historia, 86, 7-15.

BATLlORI, R. (2011). «Enseñar y aprender el espacio geográfico». A: SANTISTEBAN, A. i PAGÈs, J. (coords.). Didáctica del conocimiento del medio social y cultural en la educación primaria. Madrid: Síntesis, 249-268.

Benito, V.L.; Gil, T.M. i Grevtsova, I. (2015). «El “m-learning” en la didáctica del patrimonio: ¿Tendencias del nuevo milenio?». Íber: Didáctica de las Ciencias Sociales, Geografía e Historia, 80, 38-47. 
BLAY, M. (2013). «Desarrollo de competencias básicas y enseñanza de la geografía en la ESO». Íber: Didáctica de las Ciencias Sociales, Geografía e Historia, 74, 17-28.

Boix, G. i Olivella, R. (2007). "Los sistemas de información geográfica (SIG) aplicados a la educación: El proyecto PESIG (Portal Educativo en SIG)». A: MARRÓN, M.J.; SALOM, J. i SOUTO, X.M. (eds.). Las competencias geográficas para la educación ciudadana. València: Universitat de València, 23-32.

Buzo, I. (2016). "Los efectos territoriales de la crisis». Íber: Didáctica de las Ciencias Sociales, Geografía e Historia, 84, 31-36.

Calabuig, S., Medir, R.M. i Donaire, J.A. (2013) «Participación de los alumnos en el debate político a través del twitter». A: Díaz, J.J.; SAnTisteban, A. i Cascarejo, A. (eds.). Medios de comunicación y pensamiento critico. Nuevas formas de interacción social. Alcalá de Henares: Universidad de Alcalá y Asociación Universitaria del Profesorado de Didáctica de las Ciencias Sociales, 633-638.

Call, M.T.; Haro, M.R. i Oller, M. (2015). «Y nosotros, ¿`somos pobres?: Propuesta didáctica para dar visibilidad a la situación económica de nuestro entorno más inmediato". A: Hernández, A.M.; García, C.R. i MontañA, J.L. de la (eds.). Una enseñanza de las ciencias sociales para el futuro: Recursos para trabajar la invisibilidad de personas, lugares y temáticas. Càceres: Universidad de Extremadura y Asociación Universitaria del Profesorado de Didáctica de las Ciencias Sociales, 119-126.

Calle, M. de la (2012). «La enseñanza de la geografía ante los nuevos desafíos ambientales, sociales y territoriales». A: Miguel, R. de; LÁZARO, M.L. de i MARrón, M.J. (eds.). La educación geográfica digital. Saragossa: Asociación de Geógrafos Españoles. Grupo de Didáctica de la Geografía. Universidad de Zaragoza, 123-138.

- (2016). "Aprendizaje basado en proyectos (ABP): Posibilidades y perspectivas en ciencias sociales». Iber: Didáctica de las Ciencias Sociales, Geografía e Historia, 82, 7-12.

CAPEL, H. (2012). Filosofía y ciencia en la geografía contemporánea. Barcelona: Barcanova.

Claudino, S. (2015). "Construir un currículum con las personas, los derechos y los lugares olvidados: Retos para las ciencias sociales en el siglo XXI». A: HERNÁNDEZ, A.M.; GARCÍA, C.R. i MONTAÑA, J.L. de la (eds.). Una enseñanza de las ciencias sociales para el futuro: Recursos para trabajar la invisibilidad de personas, lugares y temáticas. Càceres: Universidad de Extremadura y Asociación Universitaria del Profesorado de Didáctica de las Ciencias Sociales, 49-65.

Gerber, R. (2001). "The State of Geographical Education in Countries Around the World». International Research in Geographical and Environmental Education, 10 (4), 349-362.

GranAdos SÁNCHEZ, J. (2010a). «La recerca en l'ensenyament de la geografia per al desenvolupament sostenible». Documents d'Anàlisi Geogràfica, 56 (2), 339-356.

- (2010b). L'educació per la sostenibilitat a l'ensenyament de la geografia: Un estudi de cas. Tesi doctoral.

- (2011). «La educación para la sostenibilidad en la enseñanza de la geografía: Un estudio de caso». Enseñanza de las Ciencias Sociales: Revista de Investigación, 10, 31-43.

Granados SÁnChez, J. i LAMAgrande, A. (2010). «Un instrumento de análisis para la investigación del uso de las tic-tac en la enseñanza de la geografía para el desarrollo sostenible». A: Ávila, R.M.; Rivero, M.P. i Domínguez, P. (eds.). Metodología de investigación en didáctica de las ciencias sociales. Institución Fernando el Católico 
y Asociación Universitaria del Profesorado de Didáctica de las Ciencias Sociales. Saragossa, 313-326.

GuevarA, J.M. i COlOMER, J.C. (2017). "Minecraft y Eduloc en historia y geografía». Íber: Didáctica de las Ciencias Sociales, Geografía e Historia, 86.

JimÉnEZ-PAlacios, R. i CuenCA López, J.M. (2015). «El uso didáctico de los videojuegos: Concepciones e ideas de futuros docentes de ciencias sociales». CLIO: History and History Teacning, 41.

Johnson, L.; Adams Becker, S.; Estrada, V. i Freeman, A. (2014). NMC Horizon Report: 2014 K-12 Edition. Austin, Texas: The New Media Consortium.

- (2015). NMC Horizon Report: 2015 K-12 Edition. Austin, Texas: The New Media Consortium.

LÁZARO, M.L. de i GONZÁLEZ, M.J. (2005). «La utilidad de los sistemas de información geográfica para la enseñanza de la geografía». Didáctica Geográfica, 7, 105-122.

LÓPEZ FACAL, R. (2013). "Competencias y enseñanza de las ciencias sociales». Íber: Didáctica de las Ciencias Sociales, Geografía e Historia, 74, 5-8.

LÓpez FERnÁNDEZ, J.A. i MARTÍnEZ MEDINA, R. (2016). "La cartografía digital y los sistemas de información geográfica a través de las publicaciones del Grupo de Didáctica de la AGE y la revista Didáctica Geográfica». A: SEBASTIÀ, R. i TONDA, E.M. (eds.). La investigación e innovación en la enseñanza de la geografía. Alacant: Publicaciones de la Universidad de Alicante, 613-624.

Luís Gómez, A. i Romero Morante, J. (2007). Escuela para todos, conocimiento académico y geografía escolar en España (1830-1953). Santander: Servicio de Publicaciones de la Universidad de Cantabria.

MACíA, X.C. (2013). "La cartografía regional de la Unión Europea como recurso didáctico para las aulas de geografía». Íber: Didáctica de las Ciencias Sociales, Geografia e Historia, 74, 37-42.

MARRÓN GAITE, M.J. (2003). "La educación geográfica en el siglo XXI y el papel de la geografía en el currículo de primaria de la nueva ley de educación (LOCE)». A: Marrón Gaite, M.J.; Moraleda, C. i Rodríguez, H. (eds.). La enseñanza de la Geografía ante las nuevas demandas sociales. Toledo: Asociación de Geógrafos Españoles. Grupo de Didáctica de la Geografía. Universidad de Castilla-La Mancha, 259-275.

MartíneZ, A. (2016). «Entender la crisis, desnaturalizar el capitalismo». Íber: Didáctica de las Ciencias Sociales, Geografía e Historia, 84, 14-24.

MELCÓn BeltrÁn, J. (1989a). La enseñanza de la geografía y el profesorado de las Escuelas Normales (1882-1915). Barcelona: Universidad de Barcelona. CSIC.

- (1989b). "La geografía y la formación de maestros en España 1836-1914». Geo Crítica, 83, 58 p.

- (1995). «La renovación de la enseñanza de la geografía en los orígenes de la España Contemporánea». Cuadernos del ICE, 14. Madrid: Ediciones de la Universidad Autónoma de Madrid.

Miguel GonZÁleZ, R. de (2013). «Aprendizaje por descubrimiento, enseñanza activa y geoinformación: Hacia una didáctica de la geografía innovadora». Didáctica Geográfica, 14, 17-36.

- (2014). «Ciencias Sociales y Didáctica de la Geografía en el currículo de educación primaria de la LOMCE». A: MARTÍNEZ, R. i TONDA, E.M. (eds.). Nuevas perspectivas conceptuales y metodológicas para la educación geográfica. Còrdova: Asociación de Geógrafos Españoles. Grupo de Didáctica de la Geografía. Universidad de Córdoba, I, 345-363. 
- (2016). "Geografía y currículo escolar en la ESO y el Bachillerato con la LOMCE: Historia de un desencuentro». A: SEBASTIÀ, R. i TONDA, E.M. (eds.). La investigación e innovación en la enseñanza de la geografía [en línia]. Alacant: Publicaciones de la Universidad de Alicante, 57-70.

<https://doi.org/10.14198/GeoAlicante2015.05>

Miguel González, R. de; Lázaro, M.L. de; Marrón, M.J. (eds.) (2012). La educación geográfica digital. Saragossa: Asociación de Geógrafos Españoles. Universidad de Zaragoza

Miguel, R. de; Lázaro, M.L.; Velilla, J.; Buzo, I. i Guallart, C. (2015). «Atlas Digital Escolar: Aprender Geografía con ArcGIS Online». A: SebASTiÀ, R. i TONDA, E. Investigar para innovar en la enseñanza de la Geografía. Alacant: Asociación de Geógrafos Españoles. Universitat d'Alacant.

Molina de la Torre, I.; Martínez Fernández, L.C. i Andrés López, G. (2016). «Utilización de la realidad aumentada en el trabajo de campo geográfico: Posibilidades y dificultades para su uso docente». A: La investigación e innovación en la enseñanza de la Geografía. Alacant: Universitat d'Alacant. Servei de Publicacions.

Morato, A.R.; Ghislanzoni, M.; Alonso, R.P. i Alcántara-Manzanares, J. (2014). «LUCATRAILS: Senderos patrimoniales guiados». A: Nuevas perspectivas conceptuales y metodológicas para la educación geográfica. Universidad de Córdoba, 607-622.

Moreno, O. i García Pérez, F.F. (2013). «Educar para la participación desde una perspectiva planetaria: Análisis de experiencias educativas en Andalucía». Íber: Didáctica de las Ciencias Sociales, Geografía e Historia, 74, 9-16.

Nogué, J. i Romero, J. (2006). «Otras geografías, otros tiempos: Nuevas y viejas preguntas, viejas y nuevas respuestas». A: Nogué, J. i Romero, J. (eds.). Las otras geografias. València: Tirant lo Blanch, 15-53.

PRIETO, F. (2012). «Aprendizaje cooperativo: Un modelo didáctico aplicado a la enseñanza de la geografía en secundaria». A: Miguel, R. de; LáZAro, M.L. de i MARRÓn GAITE, M.J. (eds.). La educación geográfica digital. Saragossa: Asociación de Geógrafos Españoles. Grupo de Didáctica de la Geografía. Universidad de Zaragoza, 529-542.

RAMIRO, E. (2009). "La inmigración: Un fenómeno natural convertido en problema». Didáctica Geográfica, 10, 161-180.

RoberTs, M. (2006). «Editorial: The future of Geography». Teaching Geography, 31 (3), 104.

Rodríguez Domenech, M.A. (2014). "Innovación en la enseñanza de las competencias goegráficas. El mobile learning y el proyecto "App Educa Cr"». A: MARTínEZ Medina, R. i Tonda Monllor, E.M. (eds.). Nuevas Perspectivas Conceptuales y Metodológicas para la Educación Geográfica, Volumen II. Còrdova: Grupo de didáctica de la AGE, 589-606.

Rojo, M.C. (2013). «Los sistemas de información geográfica para la enseñanza-aprendizaje de las ciencias sociales». Íber: Didáctica de las Ciencias Sociales, Geografía e Historia, 73, 7-17.

SouTO, X.M. (2011). «Una educación geográfica para el siglo XXI: Aprender competencias para ser ciudadano en el mundo global». Anekumene: Revista virtual. Geografía, Cultura y Educación, 1, 28-47.

- (2012). "Didáctica de la geografía y currículo escolar». A: Miguel, R. de; LÁZARO, M.L. de i MARrón, M.J. (eds). La educación geográfica digital. Saragossa: Asociación de Geógrafos Españoles. Grupo de Didáctica de la Geografía, Universidad de Zaragoza, 73-91. 
Souto, X.M. i López FACAL, R. (2016). «¿Es la crisis un contenido educativo de geografía e historia?». Íber: Didáctica de las Ciencias Sociales, Geografia e Historia, $84,7-13$.

Velilla, J. (2007). «La Ciudad: Materiales curriculares para educación secundaria elaborados desde la perspectiva de la consecución de las competencias básicas de la etapa. Experimentación en el aula». A: MARrón Gaite, M.J.; SalOM, J. i Souto, X.M. (eds.). Las competencias geográficas para la educación ciudadana. València: Asociación de Geógrafos Españoles. Grupo de Didáctica de la Geografía. Universitat de València, 291-304. 